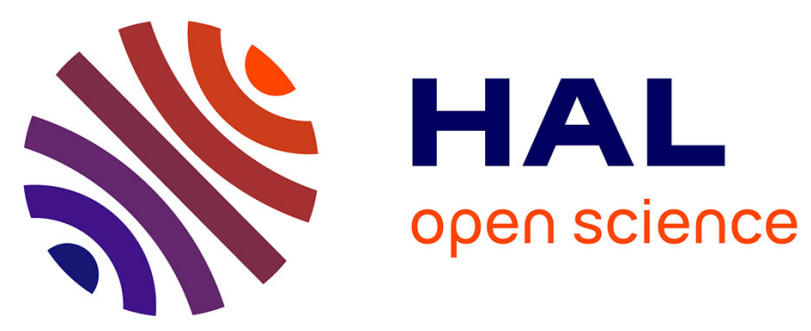

\title{
Improved hardware implementation of a TSR based MPPT algorithm for a low cost connected wind turbine emulator under unbalanced wind speeds
}

\author{
Dekali Zouheyr, Lotfi Baghli, Boumediene Abdelmadjid
}

\section{- To cite this version:}

Dekali Zouheyr, Lotfi Baghli, Boumediene Abdelmadjid. Improved hardware implementation of a TSR based MPPT algorithm for a low cost connected wind turbine emulator under unbalanced wind speeds. Energy, 2021, pp.121039. 10.1016/j.energy.2021.121039 . hal-03241817

\section{HAL Id: hal-03241817 \\ https://hal.univ-lorraine.fr/hal-03241817}

Submitted on 29 May 2021

HAL is a multi-disciplinary open access archive for the deposit and dissemination of scientific research documents, whether they are published or not. The documents may come from teaching and research institutions in France or abroad, or from public or private research centers.
L'archive ouverte pluridisciplinaire HAL, est destinée au dépôt et à la diffusion de documents scientifiques de niveau recherche, publiés ou non, émanant des établissements d'enseignement et de recherche français ou étrangers, des laboratoires publics ou privés. 


\section{Improved hardware implementation of a TSR based MPPT algorithm for a low cost connected wind turbine emulator under unbalanced wind speeds Dekali Zouheyr $^{\mathrm{a}}$, Baghli Lotfi ${ }^{\mathrm{a}, \mathrm{b}}$, Boumediene Abdelmadjid ${ }^{\mathrm{a}}$}

${ }^{a}$ LAT, Laboratoire d'Automatique de Tlemcen, Université de Tlemcen13000, Tlemcen, Alegria

${ }^{b}$ Université de Lorraine, GREEN, EA 4366, Vandouvre lès-Nancy, F-54500, France

\section{ARTICLE INFO}

\section{Article history:}

Received 00 December 00

Received in revised form 00 January 00 Accepted 00 February 00

\section{Keywords:}

Wind Turbine Emulator

Wind energy conversion system

Double fed induction generator

Maximum power point tracking DS1104

\begin{abstract}
A B S T R A C T
This paper presents the design, modeling, and the experimental build of a $1.5 \mathrm{~kW}$ relatively low-cost wind turbine emulator (WTE), based on the variable speed wind power system concept with partly rated power converters. The turbine simulator is composed of a controlled DC motor (DCM) in order to manage the static-dynamic behavior of a real wind turbine, including an ideal gearbox. This emulator is integrated into a connected wind energy conversion system chain (WECS), based on the double fed induction generator (DFIG) configuration. The latter ensures the electromechanical conversion. It allows the transfer of active and reactive power to the power grid during hypo and hyper synchronous modes. The aerodynamic emulation principle requires controlling the DC armature current with a PI controller. This leads to an electrical drive that applies a shaft torque identical to the wind turbine transmission drive train. The current reference is calculated as function of the static settings of the wind turbine and real wind speed data gives different operating points. In addition, this paper also proposes to test the TSR (Tip Speed Ratio) based MPPT algorithm to extract the maximum available power on the emulator by adjusting the rotational speed according to the actual given wind speed data. The MPPT, the DC motor control and the DFIG power control algorithms are implanted in C language, using dSPACE DS1104 control board, meanwhile simulations are done using MATLAB/Simulink. The experimental and simulation results show the effectiveness of using the controlled DC motor to emulate the wind turbine and also the great performances of the proposed MPPT structure to achieve the extraction of the maximum instantaneous power available on the drive shaft.
\end{abstract}

\section{Introduction}

In recent decades, looking for alternative energies has become very demanding, given the increased risk of excessive use of fossil fuels and their negative impact, on nature and human life [1]. According to the global wind energy congress GWEC, wind power is one of the fastestgrowing renewable energy technologies, where the rate of the cumulative global capacity of wind power production in the global market is now over $651 \mathrm{GW}$, an increase of 10 percent compared to 2018, with new installations surpassing the $60 \mathrm{GW}$ over 2019 [2].This is mainly due to its high techno-economic benefit and its renewable alternative source, environmentally friendly, as well as for solar energies $[3,4]$.
(C) 2020. Elsevier Ltd. All rights reserved.

Academic research in the renewable energy field considerably evolved, thanks to the great importance given by the energy policy of many governments around the world [5]. The subject of this paper comes within the framework of the projects at the Laboratoire d'Automatique de Tlemcen (LAT) concerns the design, implementation and intelligent management of an energy production system which is composed of two wind turbine emulator (double fed induction generator (DFIG) and synchronous generator (SG)), and a photovoltaic system [6-8].

This work is a continuation of a series of research projects in the renewable energy field at our laboratory. The lab aims to develop and study smart distributed renewable energy micro-power plants. The project includes four types of micro-power plants: $1.5 \mathrm{~kW}$ Double Fed Induction Generator Based Wind Turbine Emulator, $1.5 \mathrm{~kW}$ Synchronous Generator Based Wind Turbine Emulator, Photovoltaic system with Grid Tie

\footnotetext{
* Corresponding author.

E-mail address: zouheyr.dekali@univ-tlemcen.dz (Z. Dekali)
} 
Inverters and finally, a $250 \mathrm{~W}$ Photovoltaic micro-power plant connected through a self-made single phase Grid Tie Inverter. The main goal of this work is the development of a low-cost experimental bench for the emulation of a wind energy conversion chain based on a Double Fed Induction Generator (DFIG) [9], with the use of a DC motor controlled in current for the mechanical emulation of a real wind turbine. This system manages several scenarios and operating points in both hyposynchronous and hypersynchronous modes [10]. We can test different control laws (linear / non-linear) on both machines. Thus, it is useable as an education tool for training and for $\mathrm{PhD}$ research at an affordable cost, in the field of renewable energy.

In the literature, the DC motor is the most chosen in the wind turbine hardware emulation for the mechanical inertia driving [11]. Thanks to its linear model which ensures the proportionality between the armature current and the torque, simple torque and speed control are easy to implement with enough precision and performance [12,13].

Currently, the Double Fed Induction Generator DFIG represents one of the best high techno-economic solutions for the wind power exploitation in most wind farms around the world. It is less expensive compared to the synchronous machine [14]. Moreover, it allows direct connection of the stator to the grid and the control of the power transfer by acting on the rotor currents using an inverter / rectifier connected to the rotor [15].

This paper is organized as follows: We will first give in section II a detailed description of the overall proposed structure of this wind energy conversion system with a presentation of all the associated hardware elements of the experimental bench (machines, power electronic converters, measurements, software...). The modeling of a horizontal axis wind turbine is discussed in section III. Then, the proposed WTE with its associated MPPT algorithm is detailed in sections IV and V. The DPC based DFIG is established in the section VI. The tests results and the interpretations are given in section VII. Finally, the last section concludes the paper. YouTube videos related to the implementation and experiments can be found on:

[https:// www.youtube.com/watch v=gXJHaHWJdk0].

\begin{tabular}{|ll|}
\hline \multicolumn{2}{|c|}{ Nomenclature } \\
DFIG & Double fed induction generator \\
DCM & DC Motor \\
WECS & Wind energy conversion system \\
WTE & Wind turbine emulator \\
MPPT & Maximum power point tracking \\
TSR & Tip speed ratio \\
$\mathrm{T}_{\mathrm{DFIG}}$ & DFIG electromagnetic torque \\
$\mathrm{T}_{\mathrm{DCM}}$ & DC Motor torque \\
$\mathrm{I}_{\mathrm{DCM}}$ & DC Motor armature current \\
$\mathrm{Tt}$ & Turbine torque \\
$\mathrm{Hs}$ & High-speed shaft \\
$\mathrm{Ls}$ & Low-speed shaft \\
$\mathrm{J}$ & Moment of inertia \\
$\mathrm{f}$ & Viscous friction coefficient \\
$\mathrm{V}$ & Wind speed, $\mathrm{m} / \mathrm{s}$ \\
$\mathrm{C}_{\mathrm{p}}$ & Power coefficient \\
$\mathrm{R}$ & Blade radius, $\mathrm{m}$ \\
$\mathrm{G}$ & Gear box ratio \\
Greek letter \\
\hline
\end{tabular}

\begin{tabular}{|ll|}
\hline$\beta$ & Blade pitch angle \\
$\lambda$ & Tip speed ratio \\
$\Omega_{\mathrm{m}}$ & Mechanical speed \\
$\rho$ & Air density \\
$\omega$ & Angular speed \\
\hline
\end{tabular}

\section{Experimental hardware description}

Figure 1 shows the overall structure of the experimental hardware of the wind turbine emulator [16,17], which is constituted of a DC motor of $1.5 \mathrm{~kW}$ mechanically coupled with the DFIG shaft, The DFIG stator is connected to the grid through an autotransformer TRT 8A-400V $6 \mathrm{kVA}$ for voltage adaptation and the transfer of the generated stator active and reactive power. The used power electronics equipment consisting of a SEMIKRON Semiteach box which contain a 6-IGBT's inverter with SKHI22 drivers that drives the DFIG rotor, this inverter is called the Machine Side Converter (MSC) that imposes the current references for reaching the desired DFIG active and reactive power using the rotor-flux vector control [18].

The Semiteach has also a diode-based 3-phases rectifier, which represents the point of divergence from other known grid connected DFIG based wind turbine structures, where IGBT's controlled rectifiers are used as a Grid Side Converter (GSC). In our application, for economic reasons, we minimize equipment costs. This allows us sharing the same DC bus for both the DC motor and the DFIG and using only one DSP control board to control both motors. Hence, when the induction machine is in hypersynchronous speed operating mode, the rotor is generating active power and this power is absorbed by the chopper to drive the DC motor. The rectifier is connected to the grid through a second autotransformer TRT13A $10 \mathrm{kVA}$. Semiteach's fourth IGBT leg is used as a chopper for the DCM control [19]. The inverter has also filtering capacitors on the DC link and a big heat sinker.

To control both the DFIG and the DC motor, we use a dSPACE DS1104 single board control solution. It generates 7 PWM signals, 6 of them to control the 3-legs IGBT's machine side inverter to impose the DFIG rotor currents and one PWM signal for the DC chopper for imposing the calculated reference current. The Simple and Full PWM signals are issued by the TMS320F240 slave Digital Signal Controller of the dSPACE DS1104 board. In order to use this feature, we reprogrammed the firmware of the slave F240 DSC, leading to an optimum use of hardware and reducing the overall cost. We use the ADCs for the following measures: 2 rotor phase currents and the DC motor current using LEM LA55 Hall effect sensors ( $I_{d r}, I_{q r}$ and $I_{D C M}$ measurement), 2 stator phase voltages and the DC bus voltage using LEM LV25-P Hall effect sensors ( $V_{s a}, V_{s b}$ and $\mathrm{V}_{\mathrm{DC}}$ measurement). This uses 6 analog inputs over the 8 available ADC of the board, where 4 of them are multiplexed. The mechanical speed and the rotor angle are measured thanks to an incremental encoder with the help of the index signal and interrupt service routine to compute the absolute position of the rotor. The Control Desk ${ }^{\mathrm{TM}}$ running on the DS1104 host PC permits the visualization of the system variables in real time and the input of the reference values. 


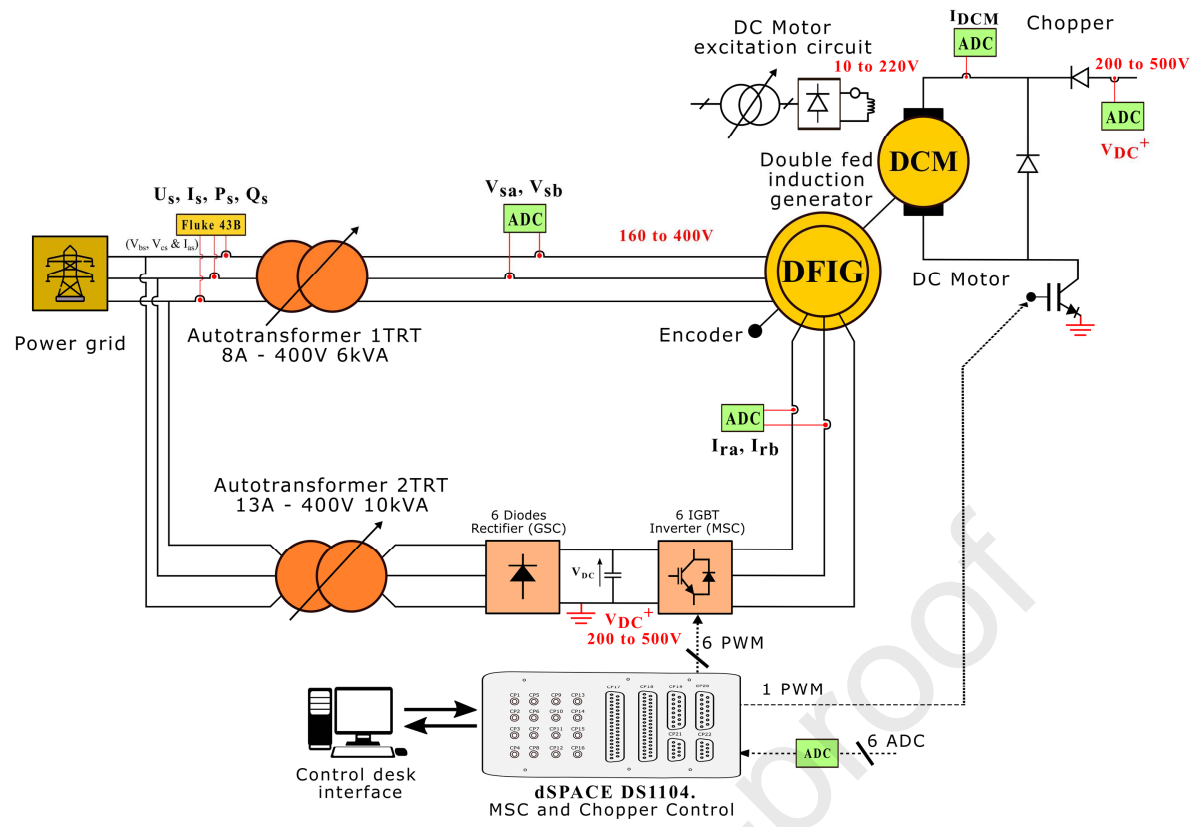

Fig. 1 - The experimental hardware structure of the WTE.

\section{Modeling and control of WTE}

In this section, we will give the model of a fixed pitch wind turbine with horizontal axis, the static-dynamic model will be used to produce a DC motor torque identical to an aerodynamic torque at the steady-state conditions depends on the wind speed and turbine characteristics [20]. The wind turbine model can be divided into two parts [21] .

\subsection{Wind turbine static model}

The kinetic energy of a column of wind of density $\rho$, driven by a velocity $V$, of length $x$, of cross section $S$ as shown in Figure 2 [22].

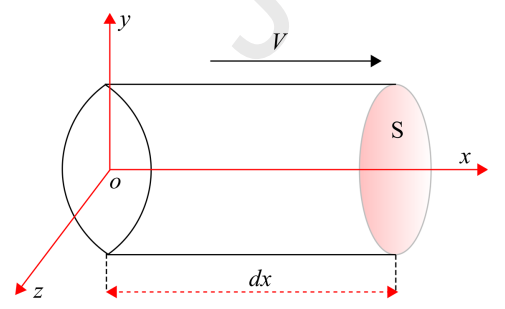

$$
\frac{d E}{d t}=\frac{1}{2} \rho S V^{3} d t
$$

Thus, we deduce the expression of the available power as [24]:

$$
P_{m}=\frac{d E}{d t}=\frac{1}{2} \rho S V^{3}
$$

The static model of the wind turbine is mainly characterized by the wind speed $V$, the blade pitch angle $\beta$ and the power coefficient $C_{p}$ [9]. The kinetic energy of wind captured by the blades in an air surface $S$ transformed into mechanical energy is given by:

$$
P_{m}=\frac{1}{2} \rho S V^{3} C_{p}
$$

Where $S$ is the surface of the air column running through the turbine blades of a radius $R$, and $\rho$ is the air density in $\left(\mathrm{kg} / \mathrm{m}^{3}\right)$. The efficiency of each wind turbine is evaluated by the power coefficient value, this value depends mainly on the blade pitch angle $\beta$ and the value of the tip-speed ratio (TSR) $\lambda$. The power coefficient value is limited to 0.59 , called Betz's limit. This theory states that a wind turbine can never convert more than $59 \%$ of the kinetic energy contained in the wind into a mechanical energy [25]. The commonly used approximation expression of the power coefficient $C_{p}$ given as:

The kinetic energy of this air column is [23]:

$$
d E=\frac{1}{2} d m V^{2}
$$

Where $d m=\rho S d l$ is mass of the wind column with $V=\frac{d l}{d t}$.So, the

$$
\left\{\begin{array}{c}
C_{p}=0.5176\left(\frac{116}{\lambda_{i}}-0.4 \beta-5\right) \exp \left(\frac{-21}{\lambda_{i}}\right)+0.0068 \lambda \\
\frac{1}{\lambda_{i}}=\frac{1}{\lambda+0.08 \beta}-\frac{0.035}{\beta^{3}+1}
\end{array}\right.
$$

expression is simplified as: 
The tip speed ratio $\lambda$ is the ratio between the turbine mechanical speed $\Omega_{t}$ and the wind speed, is defined as [26]:

$\lambda=\frac{\Omega{ }_{t} R}{V}$

Figure 3 shows the variation of the power coefficient $C_{p}$ as a function of the speed ratio $\lambda$, for some pitch angle values [27]. Each curve has its own maximum which corresponds to the maximum power that can be extracted from wind energy. This maximum is strongly influenced by the wind speed, since $\lambda$ is a consequence of $V$. Therefore, variable speed wind turbines are more efficient than fixed speed wind turbines for extracting maximum power from wind [28].

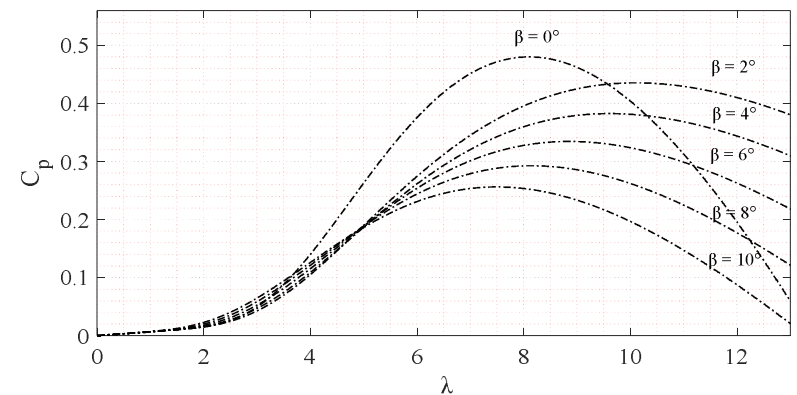

Fig. 3 - Power coefficient characteristics.

The aerodynamic torque available on the wind turbine shaft can expressed as [3]:

$T_{t}=\frac{1}{2 \Omega_{t}} \rho A V^{3} C_{p}$

\subsection{Wind turbine dynamic model}

Figure 4 illustrates the mechanical model of our WTE system, based on the simplified two-mass model, which is usually the most used in the literature to represent the forces applied to the transmission drive train of the wind power system [29].

$$
\left\{\begin{array}{c}
J_{t} \frac{d \Omega_{t}}{d t}=T_{t}-f_{t} \Omega_{t}-T_{L s} \\
J_{t} \frac{d \Omega_{m}}{d t}=T_{H s}-f_{m} \Omega_{m}-T_{m}
\end{array}\right.
$$

Where:

$\Omega_{m}, \Omega_{t}$ : The mechanical high/low-speed shaft respectively.

$T_{H s}, T_{L S}$ is the torque of the high/low-speed shaft respectively.

$J_{t}$ : Wind turbine inertia, $J_{g}$ : Inertia of the generator.

$f_{m}, f_{t}, f_{G}$ : The viscous frictions of the generator, wind turbine and the gearbox respectively.

$d_{m}, d_{f}, d_{G}$ : The stiffness coefficients of the generator, wind turbine and the gearbox respectively.

The stiffness coefficients $d_{G}, d_{t}$ and $d_{m}$ are generally low, so they can be neglected [11]. Hence, torque equations are:

$$
\left\{\begin{array}{l}
\frac{d T L_{s}}{d t}=d_{G}\left(\Omega_{t}-\Omega_{m}\right)-f_{G}\left(\frac{d \Omega_{t}}{d t}-\frac{d \Omega_{m}}{d t}\right) \\
\frac{d T H s}{d t}=d_{G}\left(\Omega_{m}-\Omega_{t}\right)-f_{G}\left(\frac{d \Omega_{m}}{d t}-\frac{d \Omega_{t}}{d t}\right)
\end{array}\right.
$$

The transmission ratio $G$ for an ideal gearbox is given by [31]:

$$
G=\frac{T_{L s}}{T_{H s}}=\frac{\Omega_{m}}{\Omega_{t}}
$$

The equivalent inertia of the WTE can be expressed by:

$$
J=\frac{J_{t}}{G^{2}}+J_{m}
$$

Figure 5 shows the equivalent mechanical model of the implanted emulator, including the opposing torques of the both machines applied on the common shaft [32]. The transmission system can be represented also by a one-mass model having an inertia equivalent to the assembly DC motor/generator and an equivalent coefficient of friction.

Fig. 5 - Mechanical model of the WTE.

However, the stiffness coefficients $d_{G}, d_{t}$ and $d_{m}$ are generally low, so they can be neglected [33]. Hence, the fundamental mechanical equation of the emulator in the electrical generator side is giving as:

$J \frac{d \Omega_{m}}{d t}=T_{D C M}-T_{m}$ [30]:

Fig. 4 - Two mass schematic model of WTE drive train

The dynamics of the low and high-speed shaft can be described by 
The equivalent inertia $J$ applied on the high-speed shaft (generator side) is becomes as:

$$
J=J_{D C M}+J_{m}
$$

The overall wind turbine model, including its both static-dynamic parties can be generalized in figure $6[6]$.

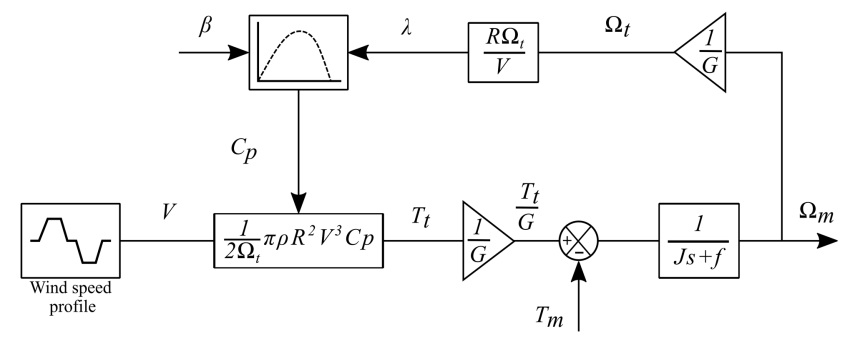

Fig. 6 - Overall model of a variable-speed WTE.

\subsection{Wind speeds distribution based on Weibull model}

The Weibull function makes possible to characterize the frequency distribution of wind speeds over a given period in different locations [34]. However, in most cases, this distribution is used for a one-year period. It is defined by the following equation [35]:

$$
f(V)=\frac{k}{c}\left(\frac{V}{c}\right)^{k-1} \exp \left(-\left(\frac{V}{c}\right)^{k}\right)
$$

Where $f(V)$ is the Weibull probability density function (PDF). $c$ is the scaling factor. It is related to the average wind speed by the form factor $k$. $k$ is the Weibull shape factor. The latter describe the distribution of wind speed. Thus, the cumulative distribution function (CDF) is obtained by integrating the Weibull probability density function [36]:

$P(V)=1-\exp \left(-\left(\frac{V}{c}\right)^{k}\right)$

The mean wind speed can be expressed by:

$\bar{V}=\frac{1}{n} \sum_{i=1}^{n} V_{i}$

In order to analyses the distribution of the wind speed according to the Weibull law, it's required to estimate the Weibull shape factor $k$ and the scaling factor $c$. Weibull shape factor $k$ is estimated using [37]:

$$
k=\left(\frac{\sigma}{\bar{V}}\right)^{-1.086}
$$

$$
\sigma=\sqrt{\frac{1}{n-1} \sum_{i=1}^{n}\left(V_{i}-\bar{V}\right)^{2}}
$$

So, scaling factor $c$ is:

$$
c=\frac{\bar{V}}{\Gamma\left(1+\frac{1}{k}\right)}
$$

where $\Gamma$ is the gamma function.

\subsection{Rayleigh distribution}

Rayleigh probability density is a particular case of Weibull's law when $k=2$ [38]. Thus, the scaling factor $c$ is determined as follow:

$c=\frac{2 \bar{V}}{\sqrt{\pi}}$

The probability density function becomes:

$f(V)=\frac{\pi}{2} \frac{V}{\bar{V}^{2}} \exp \left(-\left[\frac{\pi}{4}\left(\frac{V}{\bar{V}}\right)^{2}\right]\right)$

While the cumulative distribution function is:

$$
P(V)=1-\exp \left(-\left[\frac{\pi}{4}\left(\frac{V}{\bar{V}}\right)^{2}\right]\right)
$$

The main advantage of Rayleigh's law is its simplicity. The Rayleigh law now depends only on the mean value of the wind speed.

The site chosen for our study is the current location of our laboratory at Tlemcen in North Africa (Fig. 7). the wind measurements over a year are taken from NASA Power data [39].

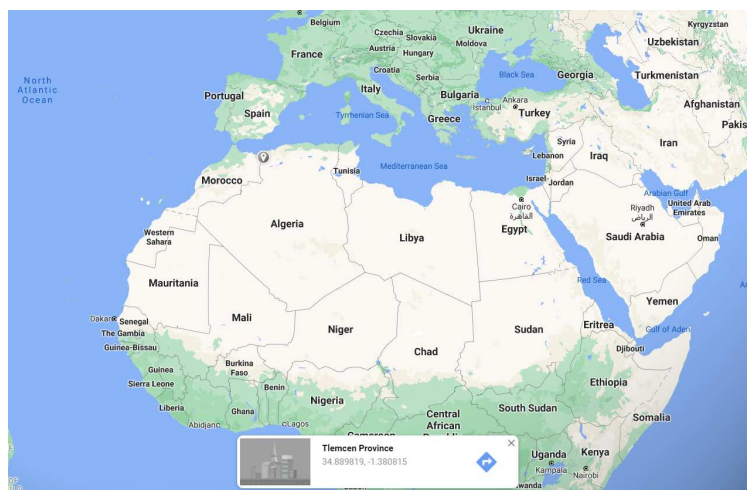

Fig. 7 - location of the studied site.

Where $\sigma$ is the standard deviation of wind speed. 
Figure 8 shows the average wind speed over Tlemcen at $50 \mathrm{~m}$ altitude during 2020 [40]. Mainly, this speed varies between $2.5 \mathrm{~m} / \mathrm{s}$ and $7.5 \mathrm{~m} / \mathrm{s}$ around an average value of $5.1 \mathrm{~m} / \mathrm{s}$. It is noted that the mean value of wind speed is high during autumn, reaching sometimes $13.75 \mathrm{~m} / \mathrm{s}$.

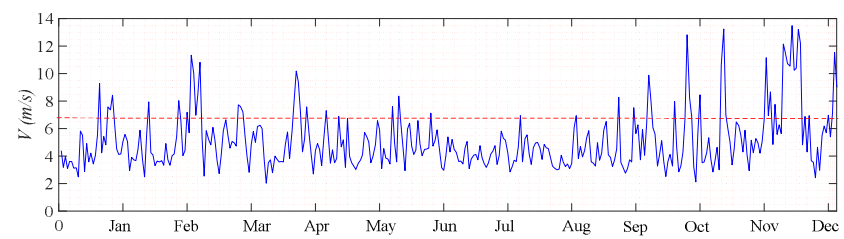

Fig. 8 - Wind speed Data at Tlemcen in 2020.

Figure 9 presents the Rayleigh probability distributions function PDF and Rayleigh cumulative distributions function CDF for all speed ranges. Rayleigh PDF seems to give a reasonable fit to the measured wind speed data, because most of wind speeds are in the range of 3-7 m/s during all the year (Figure 9.a), as well as the cumulative distribution function which increases strongly in this range (Figure 9.b). Therefore, we can classify it as a normal distribution. This last can judge the efficiency of the Rayleigh distribution.


Fig. 9 - a) Rayleigh probability distributions function PDF, b) Rayleigh cumulative distributions function $\mathrm{CDF}$.

The wind speed data analyzed above was incorporated into the lab setup, applying a similar curve distribution to generate aerodynamic drive torque. The time interval has been reduced to one minute while maintaining the same speed distributions.

\section{TSR Based MPPT algorithm structure}

Mainly, the operating ranges of the variable speed wind turbine can be divided into three basic regions as shown figure 10 [41]. The MPPT operation part included in zone II Between (B-C), is the most important part of the WTE, considering the evolution of energy production according to the development on the wind speeds. The MPPT in this stage has the role of maintaining $C_{p}$ in a maximum value $\left(C_{p}=C_{p \max }\right)$ by adjusting the rotor rotational speed according to the wind speed change, hence, the tip speed ratio keeps its optimum value $\left(\lambda=\lambda_{\text {opt }}\right)$. Besides, the mechanical speed is controlled at the optimum turbine rotational speed for each captured wind speed, hence, the generated electromagnetic torque become linked into this speed, consequently, the quadrature rotor current of the generator $I_{q r}[42]$.

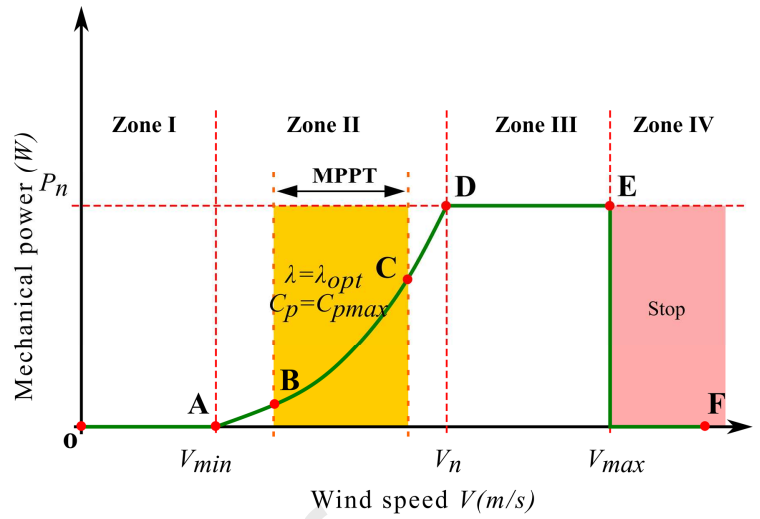

Fig. 10 - Operational range of a variable speed based WTE.

The TSR structure is the most used MPPT algorithms, thanks to its efficiency, especially the simplicity of implementation [43]. The principle is to keep the tip speed ratio (TSR) to an optimum value $\lambda_{\text {opt }}$ that corresponds the maximum of $C_{p \max }$ (Fig. 11.a), hence the maximum of the extracted power. Therefore, it is necessary to maintain the WTE rotational speed at this operating point by adjusting the generator speed with a speed control loop [44].
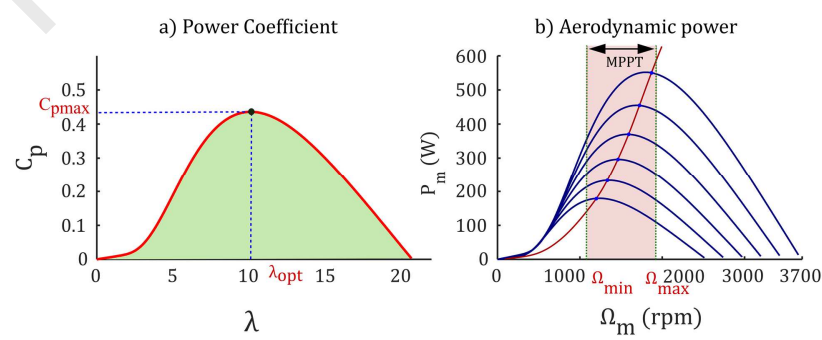

Fig. 11 - TSR principle based MPPT algorithm.

The WTE output mechanical power available on the DFIG-DCM common shaft at different wind speeds, therefore, the WTE rotational speed (Fig. 11.b) [45]. The red line intersection points with the curves present the maximum power that needs to be extracted to achieve optimum operating point. Therefore, we apply TSR based MPPT algorithm to extract as much power as possible in the limited region colored, the interval of this limitation is chosen to be adaptable with the controller performances, also the hardware protection against overvoltage. For our emulator, we set $\beta$ at $2^{\circ}$ which corresponds to a maximum power coefficient $C_{\text {pmax }}$ of 0.43 for an optimum tip speed ratio $\lambda_{\text {opt }}$ of 10.22 [46]. The optimal speed reference is expressed as:

$\Omega_{t}^{*}=G \frac{\lambda_{\text {opt }}}{R} V$ 


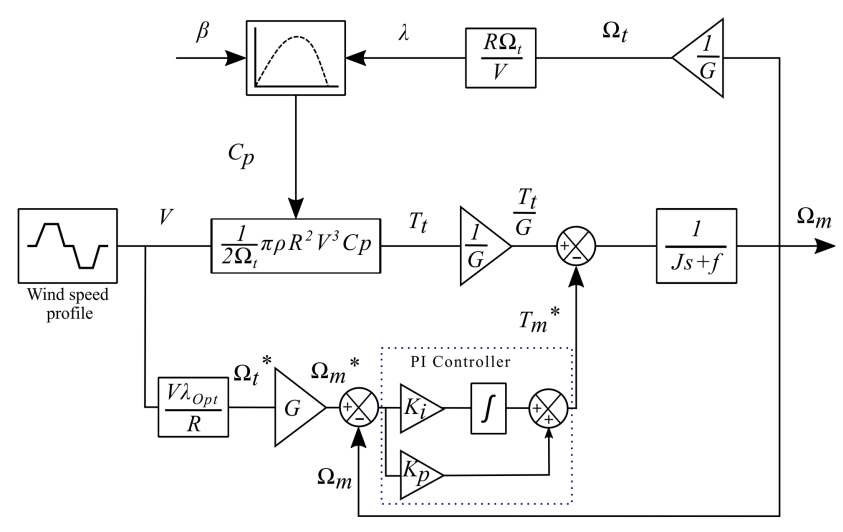

Fig. 12 - TSR based MPPT algorithm block diagram.

The block diagram of the TSR based MPPT algorithm is given by Figure 12 [47]. The PI regulator is used to reduce the error between the optimal speed reference calculated in Eq (22) and the actual speed. This algorithm requires the accurate measurement of wind speed using an anemometer, this latter has an additive cost and it becomes a disadvantage for small turbine, add to that the inconvenience of the limited operating area.

\section{The proposed WTE}

The principle of emulating a wind turbine is to create aerodynamic torque from the controlled DC motor [19]. Figure 13 shows the proposed structure of the proposed WTE that is implanted at our laboratory [32]. The controlled DC motor provides a variable output torque, which we consider equal to an adapted aerodynamic torque via an ideal gearbox [48].

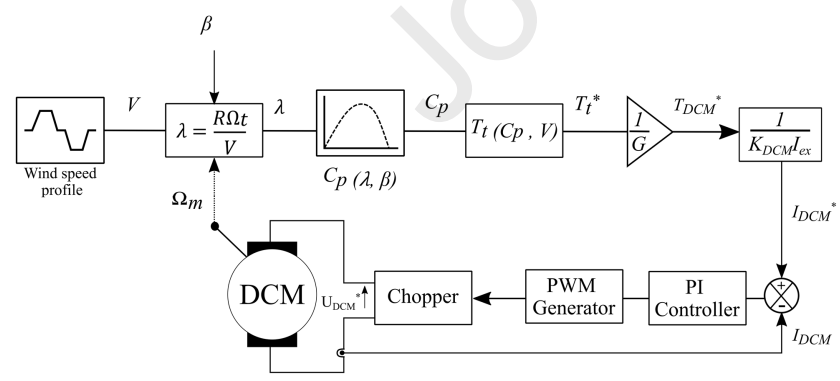

Fig. 13 - Overall diagram of the wind turbine emulator.

Equation (23) indicates the proportionality between the armature current and the DC motor torque [49]:

$T_{D C M}=K_{D C M}$

Where $K$ is the product of the electromotive force coefficient $K_{D C M}$ and the excitation current $I_{e x}$. Therefore, while keeping this coefficient constant, controlling the torque, is done by acting on the armature current [50]. The reference current $I_{D C M}{ }^{*}$ is calculated when applying a wind speed profile on the static-dynamic model of the wind turbine. Thus, the armature current follows the shape of the wind speed curve. So are the torque $T_{D C M}{ }^{*}$ and the supply voltage $U_{D C M}{ }^{*}$ [7]. The calculated reference current formula which relates the typical wind speed to the armature current is expressed as follows:

$I_{D C M}^{*}=\frac{\rho \pi R^{2} C p}{2 G K \Omega_{m}} V^{3}$

The proposed wind speed values interval allows testing transient of the transfer of the generated power between the power grid and the DFIG stator-rotor during operating modes: hyper synchronous, and hypo synchronous mode [51].

\section{DFIG integrated into WTE}

The next part consists of keeping the mechanical training structure and adding the control algorithm of the MSC in order to produce active and reactive power (Fig .14) [17,33]. Therefore, the MPPT control loop is cascaded with the $I_{q r}$ PI controller, consequently, the speed loop determines the desired reference of the active power $P_{s}{ }^{*}$. 


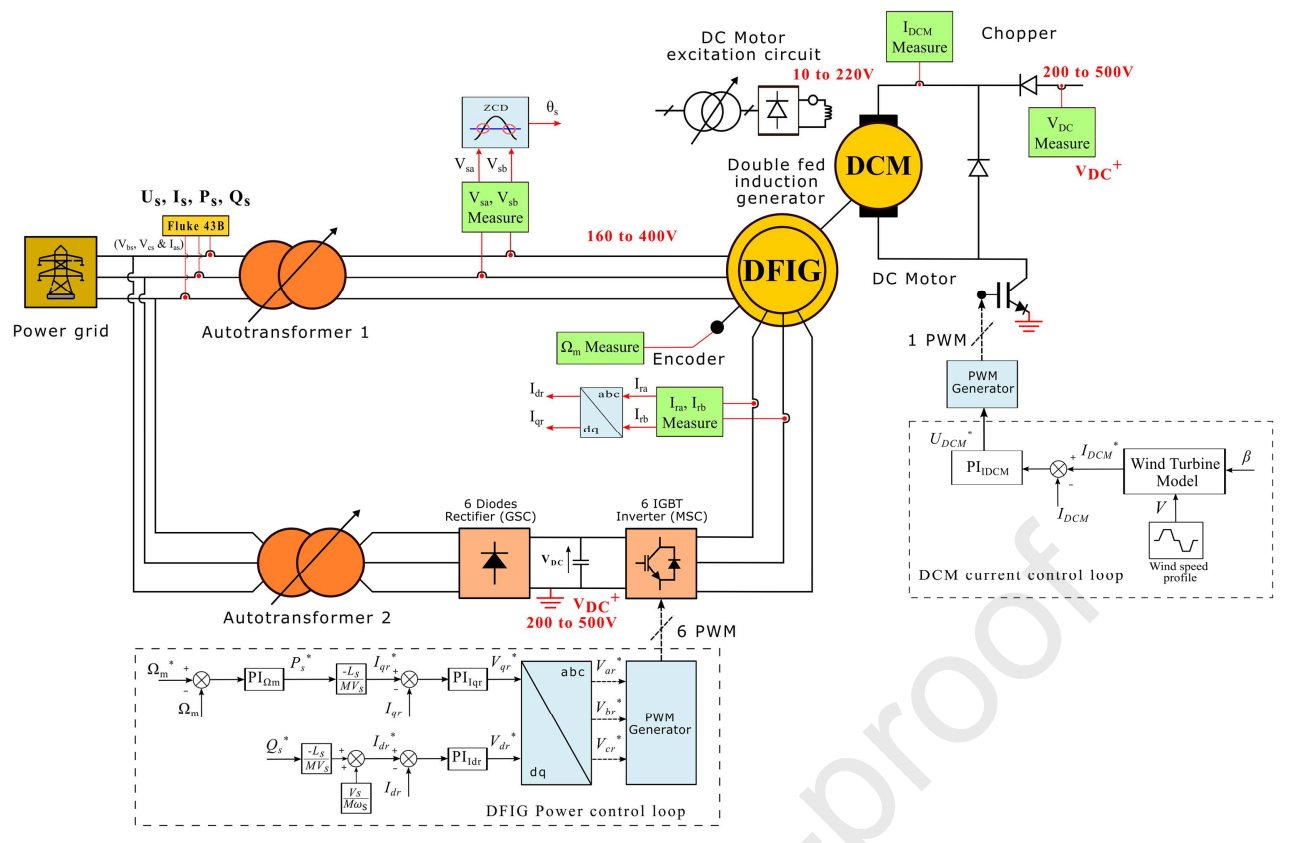

Fig. 14 - Overall scheme of the proposed WTE.

In order to integrate the MSC control part, the generator model is presented. The DFIG simplified $d q$ model is written as [51,52]:

$$
\left\{\begin{array}{c}
V_{d r}=R_{r} I_{d r}+\sigma L_{r} \frac{d I_{d r}}{d t}-\omega_{r} \sigma L_{r} I_{q r} \\
V_{q r}=R_{r} I_{q r}+\sigma L_{r} \frac{d I_{q r}}{d t}+\omega_{r} \sigma L_{r} I_{d r}+\omega_{r} \frac{M V_{s}}{\omega_{s} L_{s}}
\end{array}\right.
$$

Where $\sigma=1-\frac{M^{2}}{L_{s} L_{R}}$ is the leakage coefficient, $R_{r}$ is the resistance of the rotor, $L_{s}$ and $L_{r}$ are the stator and the rotor inductances. $M$ is the statorrotor mutual inductance [53]. The DFIG stator active and reactive power is expressed according of the direct and quadrature rotor currents as [14]:

$\left\{\begin{array}{c}P_{s}=-\frac{M V_{s}}{L_{s}} I_{q r} \\ Q_{s}=-\frac{M V_{s}}{L_{s}} I_{d r}+\frac{V_{s}^{2}}{\omega_{s} L_{s}}\end{array}\right.$

where the electromagnetic torque of the machine is given by:

$$
T_{g}=-p \frac{M}{L_{s}} \varphi_{s} I_{q r}
$$

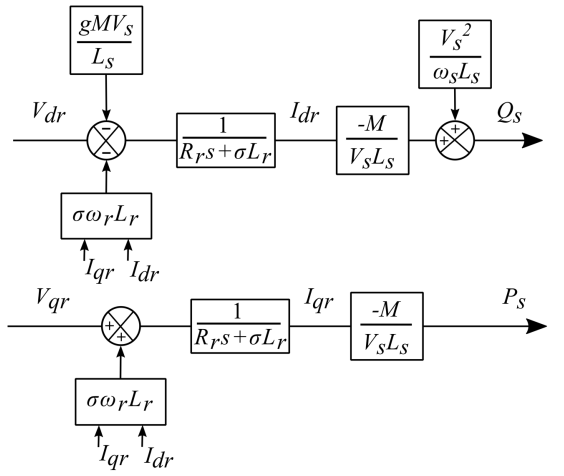

Fig. 15 - Block diagram of the DFIG.

According to the rotor voltage equations, the rotor currents $I_{d r}$ and $I_{q r}$ are controlled by the rotor voltages $V_{d r}$ and $V_{q r}$, respectively. Hence, the adjustment of the stator reactive power $Q_{s}$ is done by acting directly on the d-axis rotor current $I_{d r}$ through the PI controller loop, while the active power $P_{s}$ control is done by the action on the q-axis current $I_{q r}$ [55]. Figure 16 illustrates the $d q$ current loops, the active and reactive power are controlled through two similar PI control loop, and independently thanks to the introduction of decoupling terms in the current loops [8].

The model is summarized in the block diagram of Figure 15 [54]. 

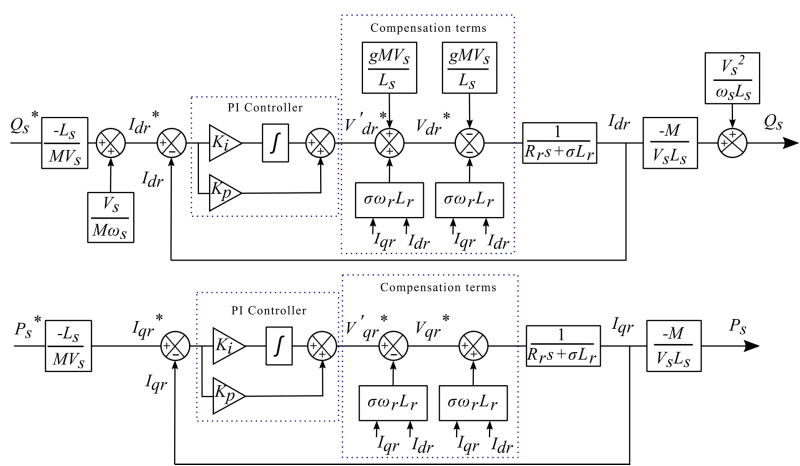

Fig. 16 - Diagram of the DFIG direct power control using PI controllers.

\section{Results and discussions}

In order to validate the effectiveness of the proposed WECS structure, we conduct experimental tests that affirmed before by the simulation validation under Matlab Simulink framework. They consist of introducing different wind speed profiles that covers the operating modes. At every moment, the control applies a DC motor torque identical to the one of the emulated wind turbine, imposing the driving speed. In addition, the experiments test the MPPT efficiency by TSR method. We apply two tests:

\subsection{First test: wind profile in a sinusoidal shape}

As a first test, we apply a slow sinusoidal variation on the wind speed which varies between 5.5 and $8.5 \mathrm{~m} / \mathrm{s}$. The slow transition of the sinusoidal shape makes it possible to observe well the electro-mechanical phenomena of the WTE during the slow transition between the hypersynchronous towards the hypersynchronous, passing by the synchronous speed at $1500 \mathrm{rpm}$ which correspond to a wind speed of 7 $\mathrm{m} / \mathrm{s}$ (Fig. 17).

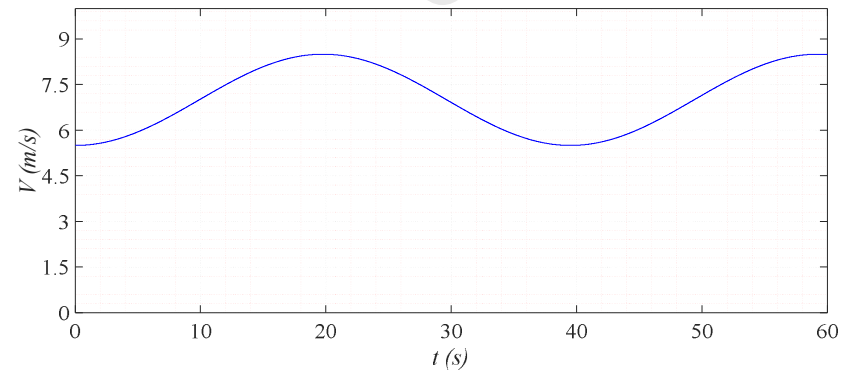

Fig. 17 - Wind speed profile.

The figure (18.a) shows the good tracking accuracy between the measured armature current $I_{D C M}$ and the calculated reference $I_{D C M}{ }^{*}$ thanks to the PI current controller. The necessary DC motor voltage $U_{D C M}{ }^{*}$ that is outputted by the current controller is limited to $220 \mathrm{~V}$ for the protection of the DC motor (Fig. 18.b). When it reaches this limit, the current decreases inevitably. This condition of current decrease during saturation is not the same for both experimental and simulation tests, so the currents $I_{D C M(S I M)}$ and $I_{D C M(E X P)}$ are not identical during this test period.
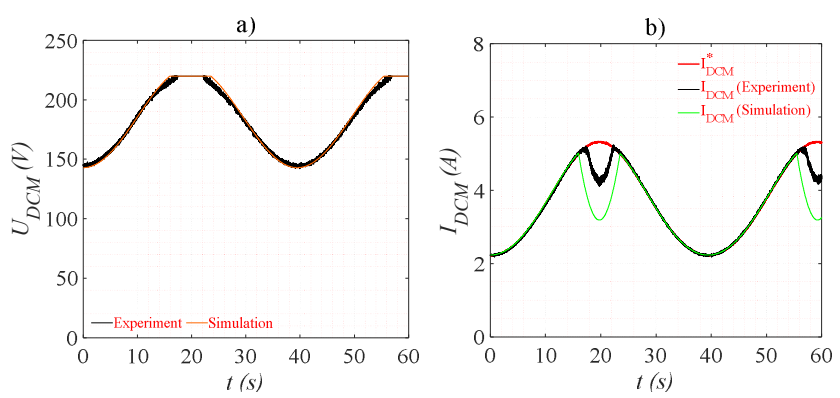

Fig. 18 - a) DC armature current, b) DC motor voltage.

We then get the WTE torques: turbine torque, which is adapted through the gearbox ratio to get a DC motor torque, they have the same form of the wind speed curve and they are opposed. Harmonic torques due to the gradient and tower shadow effects are neglected and we consider the gearbox as ideal (Fig. 19).



Fig. 19 - WTE Torques.

The tip speed ratio $\lambda$ remains stable around its optimum value $\lambda_{\text {opt }}$ (Fig 20.b). The value of the power coefficient $C_{p}$ is around 0.42 (Fig 20.a), which allows the production of a significant power.
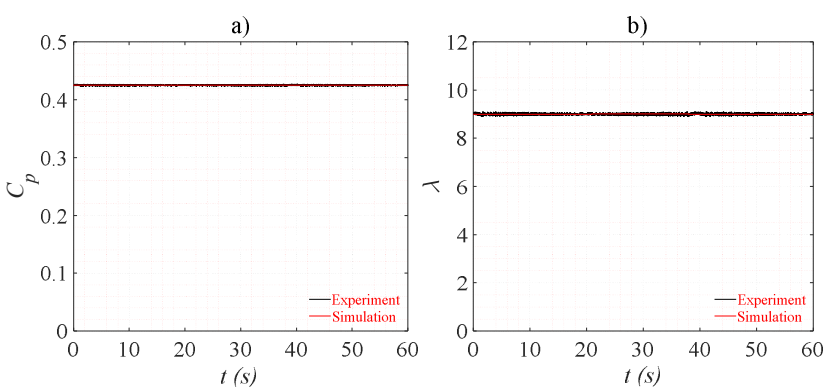

Fig. 20 - a) Power coefficient, b) Tip speed ratio.

The WTE rotates at an optimum speed $\Omega_{\text {opt }}$, that is adjusted perfectly by the speed control loop using PI controller (Fig 21.b), The optimum reference speed $\Omega_{\text {opt }}{ }^{*}$ is imposed by the MPPT algorithm loop based on the TSR structure. As well, the mechanical speed is transmitted slowly 
between operating modes on the limited zone of the MPPT operation, and they will be fixed as soon as it reaches its up-maximum value at $1800 \mathrm{rpm}$ (Fig 21.a), the generated power is consequently fixed also.
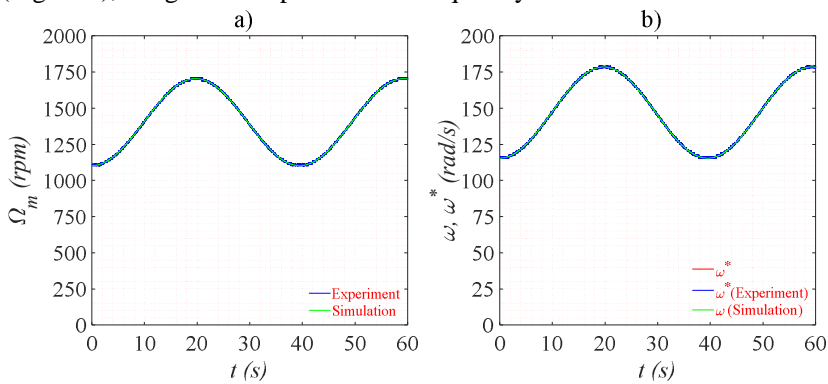

Fig. 21 - a) WTE Mechanical speed, b) WTE speed control.

The MPPT based TSR algorithm shows the capability to reach the maximum of the extracted power during the transition speeds over a significant range (Fig. 22). A negative power means that it is injected into the grid. The efficiency of both PI current controllers maintains the accuracy of the active and reactive power trajectory. The DFIG consumes a reactive power of $450 \mathrm{VAr}$ to be fluxed.
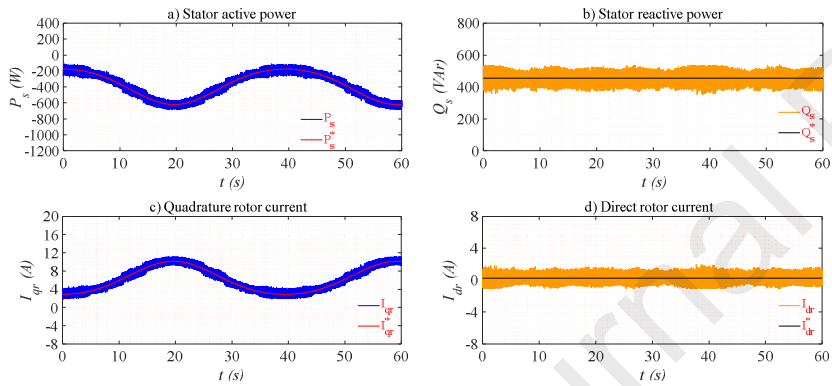

a) Simulation results.
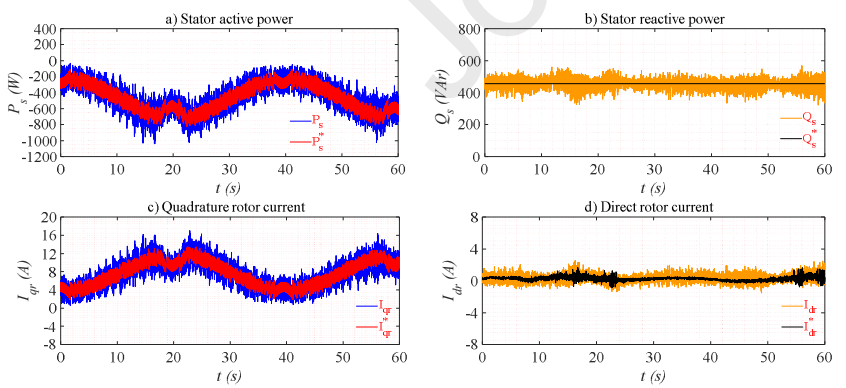

b) Experimental results.

Fig. 22 - DFIG active and reactive power.

Figure 23 shows the required rotor voltages $V_{d r}$ and $V_{q r}$ to achieve the needed power. The stator voltage in the experiments is a little disturbed due to measurement fluctuations, the same goes for the DC voltage measurements. For the simulation tests, we use a perfect power source. Thus, The DC bus and the stator voltages stay constant.


a) DFIG Rotor voltages.
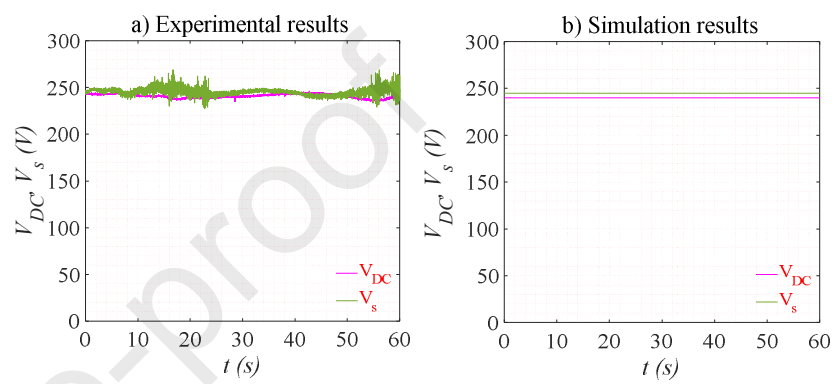

b) DFIG Rotor, Stator and DC Bus voltages.

Fig. 23 - DFIG voltages.

\subsection{Second test: approximate real wind speed profile}

For this test, we have changed the wind speed reference, this time we apply a real wind speed profile to get closer to the actual behavior of a wind turbine power plant (Fig. 24). Therefore, the wind data will be an array of random values from 5.5 to $8.75 \mathrm{~m} / \mathrm{s}$ includes unbalanced transitions between both operating modes.

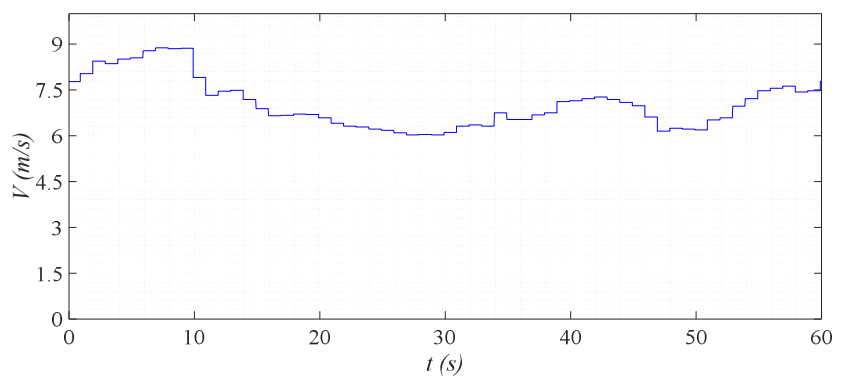

Fig. 24 - Wind speed profile.

The control loop based on the numerical PI controller for the DC motor current shows high performances as the previous tests (Fig. 25), as well as the speed control loop (Fig. 26). 

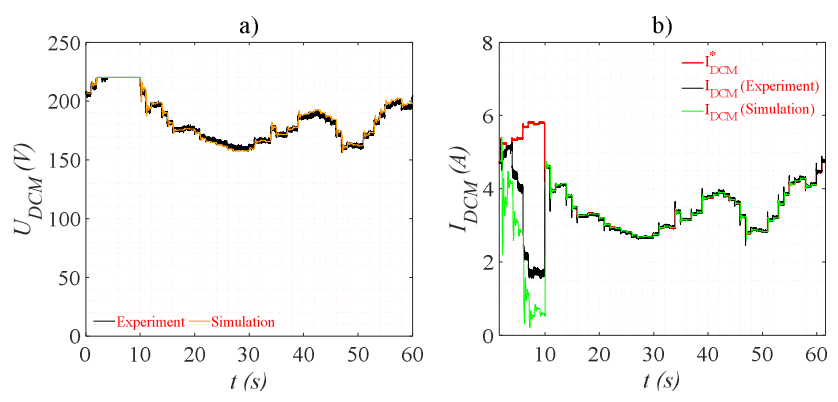

Fig. 25 - a) DC armature current, b) DC motor voltage.
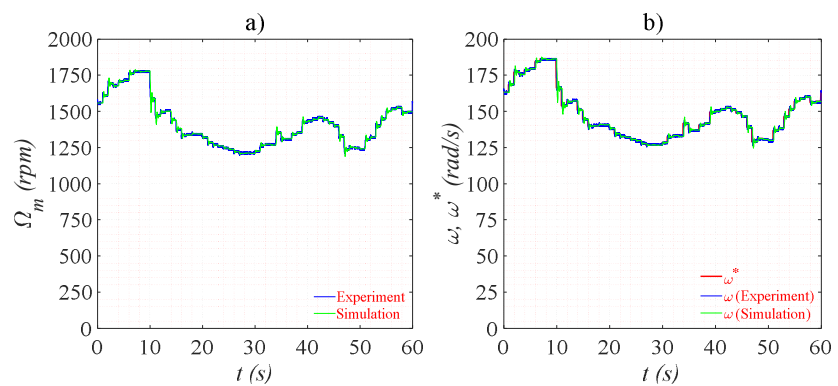

Fig. 26 - a) WTE Mechanical speed, b) WTE speed control.

The resulting curves show the same dynamic performances of the WTE control as the previous experiment. The generated torques has a curve identical to that of the wind speed with negligible harmonics (Fig. 27). The high wind speeds between 8 and $10 s$ require a relatively important shaft drive torque, which therefore requires a supply DC motor voltage greater than the limitation at $220 \mathrm{~V}$, necessarily a progressive decrease in armature current, which was accompanied by decrease in the electromagnetic torque with an instantaneous cancellation of the produced energy (Fig. 20).

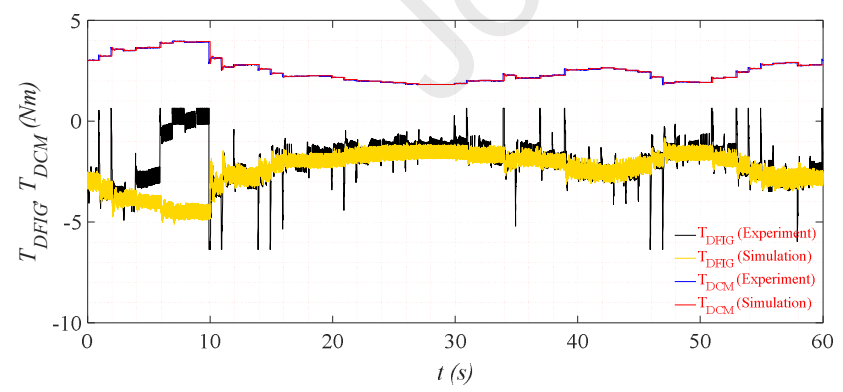

Fig. 27 - WTE Torques.

The hardware harmonics have little influence on the quality of the tip speed ratio curve (Fig. 28.b) and the power coefficient quality (Fig. 28.a).


Fig. 28 - a) Power coefficient, b) Tip speed ratio.

The estimated active power is still influenced by fluctuation of the measurement which is not so perfect. Thus, it inevitably affects the power quality. In the experimental, the generation of the active energy is stopped when the DC motor voltage reaches its imposed limit. The reactive power of the machine is compensated, so the machine consumes a direct rotor current of 8 A (Fig. 29).
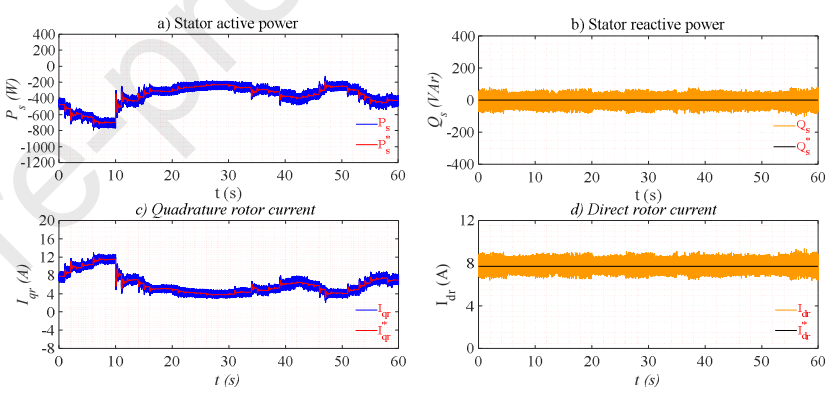

a) Simulation results.


b) Experimental results.

Fig. 29 - DFIG active and reactive power.

The needed rotor voltages vary according to the actual wind speed references, while the stator and DC bus voltages remain around their nominal values, with some fluctuations (Fig. 30). 

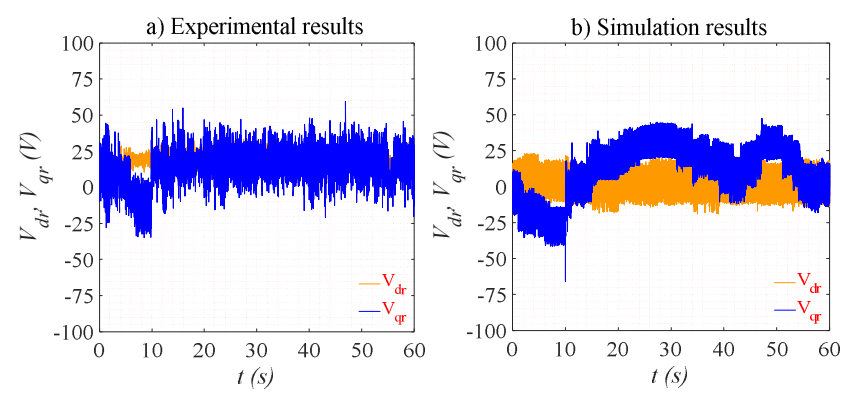

a) DFIG Rotor voltages.
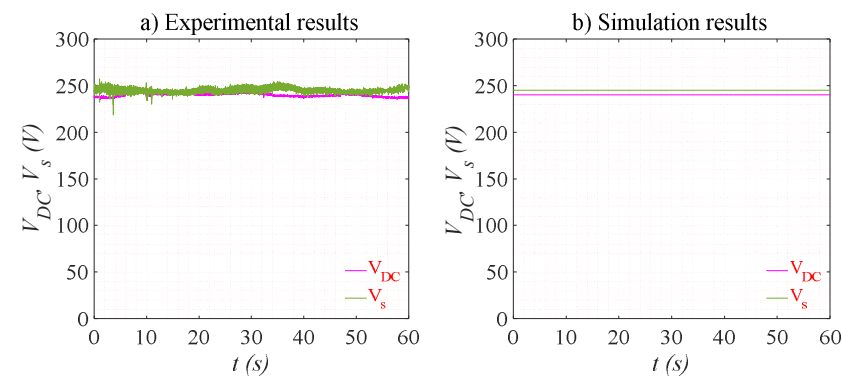

b) DFIG Rotor, Stator and DC Bus voltages.

Fig. 30 - DFIG voltages.

The spikes on the active power are due to high frequency noise from the measured rotor current components in Park reference frame $\left(I_{d r}\right.$ and $\left.I_{q r}\right)$ of the DFIG. The low-pass filter bandwidth is chosen wide to avoid any lag in the current measurement, but it let pass more hi-frequency contents. High frequency fluctuations also influence electromagnetic torque, the tip speed ratio and power coefficient, unlike simulation tests, where the fluctuations are negligible. In addition to the good physical emulation of the real wind turbine as shown by the tests, the control loops based on PI controllers show good robustness and high performance in the precise monitoring of references of the optimum rotational speed, as well as the imposed armature current.

The experimental and simulation results are approximately identical, thanks to the correct identification of the parameters of both machines and the WTE, therefore, the WTE app was created using the Matlab App Designer, in order to analyze and display the WTE steady-state outputs values (powers, currents, voltages... etc.), according to the WTE inputs which are the instantaneous wind speed, the pitch angle, the ratio of the gearbox... etc [8].

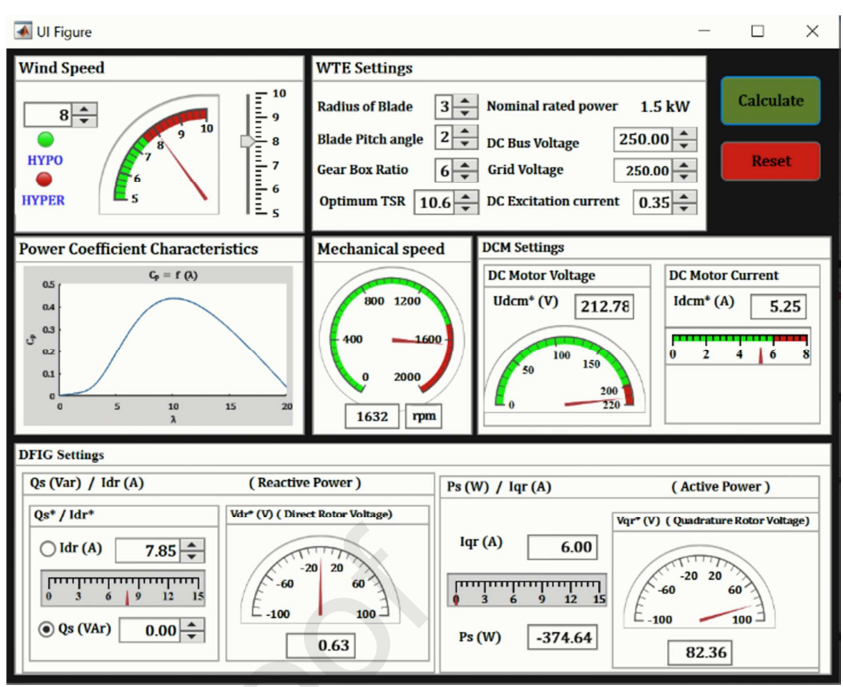

Fig. 31 - WTE steady-state App interface.

The App interface makes possible the definition of the limitation of the hardware protection before starting the simulations or the experiments.

\section{Conclusion}

A relatively low-cost wind energy conversion system was constructed successfully for an emulator test bench, with its associated power electronics and control system and program. The experimental results that affirmed by the simulation tests confirm the validity of the proposed WECS structure and its high performance by using a current controlled DC motor for the emulation of the wind turbine behaviors. On the other hand, the TSR based MPPT algorithm structure is very satisfactory for the extraction of the maximum power available. The DFIG control allows the injection of the active and reactive power to the grid.

The accuracy given by PI control loop affirms the advantage of using this kind of control law sufficiently in wind power system. add to that, the successful implantation of the MPPT algorithm demonstrates the feasibility of the tips speed ratio technique as one of the most efficient solution for the extraction of wind energy.

This work allows the integration of this emulator in another test bench based on a Synchronous Generator and also for testing several linear and nonlinear control algorithms, either for educational use or for the development of research studies. According to national needs in MENA region, there is a need for training a new generation of engineers and researchers in the field of production of renewable energies.

\section{Declaration of competing interest}

The authors declare that they have no known competing financial interests or personal relationships that could have appeared to influence the work reported in this paper. 


\section{Acknowledgements}

This work is supported by the Direction Generale de la Recherche Scientifique et du Developpement Technologique (DG RSDT).

\section{Appendix}



Fig. 32 - WTE Lab Hardware setup.

Table 1 - WTE hardware component.

\begin{tabular}{lc}
\hline Component & Name \\
\hline 1,2 & Autotransformer (stator side, rotor side \\
respectively) \\
3,4 & DFIG \& DCM respectively \\
5 & PC \\
6 & Inverter and Rectifier \\
7 & Fluke 43B Power Quality Analyzer \\
8,9 & Measure interfaces (DCM \& DFIG respectively) \\
10 & DS1104 interface \\
11 & Rheostat \\
12 & $\mathrm{~V}_{\mathrm{S}}, \mathrm{V}_{\mathrm{DC}}$ Measures \\
13 & Power supply (DCM excitation) \\
&
\end{tabular}

Table 2 - WTE Settings.

\begin{tabular}{lc}
\hline Settings & Parametres \\
\hline $\mathrm{Pn}$ & $1.5 \mathrm{~kW}$ \\
$\Omega \mathrm{m}$ & $1500 \mathrm{rpm}$ \\
$\mathrm{R}$ & $3 \mathrm{~m}$ \\
$\mathrm{G}$ & 7 \\
$\beta$ & $2^{\circ}$ \\
$\lambda \mathrm{opt}$ & 11.68 \\
$\rho$ & 1.225
\end{tabular}

\section{References}

[1] Shivsharan, B. A., Magade, P. B., Chavan, S., Magade, S. Experimental Design, Development and Testing of Novel Aluminum Mini Wind Turbine. Materials Today: Proceedings. 2020,S2214785320367973. https://doi.org/10.1016/j.matpr.2020.09.106

[2] Global Wind Report 2019. Global Wind Energy Council, http://www.gwec.net; 2019[accessed 13 March 2020].

[3] Xu, D., Blaabjerg, F., Chen, W., Zhu, N. Advanced Control of Doubly Fed Induction Generator for Wind Power Systems. 2018.

[4] Aktaş A, Kırçiçek Y. A novel optimal energy management strategy for offshore wind/marine current/battery/ultracapacitor hybrid renewable energy system. Energy 2020;199:117425. https://doi.org/10.1016/j.energy.2020.117425.

[5] Chau TK, Yu SS, Fernando TL, Iu HH-C, Small M. A Novel Control Strategy of DFIG Wind Turbines in Complex Power Systems for Enhancement of Primary Frequency Response and LFOD. IEEE Trans Power Syst 2018;33:1811-23. https://doi.org/10.1109/TPWRS.2017.2726160.

[6] Dekali Z, Baghli L, Boumediene A, Djemai M. Control of a Grid Connected DFIG Based Wind Turbine Emulator. 2018 5th Int. Symp. Environ.-Friendly Energ. Appl. EFEA, Rome: IEEE; 2018, p. 1-6. https://doi.org/10.1109/EFEA.2018.8617049.

[7] Dekali Z, Baghli L, Boumediene A. Experimental Emulation of a Small Wind Turbine Under Operating Modes Using DC Motor. 2019 4th Int. Conf. Power Electron. Their Appl. ICPEA, Elazig, Turkey: $\quad$ IEEE; $\quad 2019, \quad$ p. $1-5$. https://doi.org/10.1109/ICPEA1.2019.8911194.

[8] Dekali Z, Baghli L, Boumediene A. Indirect power control for a Grid Connected Double Fed Induction Generator Based Wind Turbine Emulator. 2019 Int. Conf. Adv. Electr. Eng. ICAEE, Algiers, Algeria: IEEE; 2019, p. 1-6. https://doi.org/10.1109/ICAEE47123.2019.9014778.

[9] Shehata EG. Sliding mode direct power control of RSC for DFIGs driven by variable speed wind turbines. Alex Eng J 2015;54:1067-75. https://doi.org/10.1016/j.aej.2015.06.006.

[10] Amjith LR, Bavanish B. Design and analysis of 5 MW horizontal axis wind turbine. Mater Today Proc 2020:S2214785320368991. https://doi.org/10.1016/j.matpr.2020.09.202.

[11] Lim CW. A demonstration on the similarity of pitch response between MW wind turbine and small-scale simulator. Renew Energy https://doi.org/10.1016/j.renene.2018.06.008

[12] Arevalo F, Estrada P, Pozo N, Pozo M. Wind generation emulator using a DC machine. 2017 IEEE Second Ecuad. Tech. Chapters Meet. ETCM, Salinas: IEEE; 2017, p. 1-6. https://doi.org/10.1109/ETCM.2017.8247447.

[13] Benaaouinate L, Khafallah M, Mesbahi A, Martinez A. Development of a useful wind turbine emulator based on permanent magnet DC motor. 2017 14th Int. Multi-Conf. Syst. Signals Devices SSD, Marrakech: IEEE; 2017, p. 44-8. https://doi.org/10.1109/SSD.2017.8166972.

[14] Kadri A, Marzougui H, Aouiti A, Bacha F. Energy management and control strategy for a DFIG wind turbine/fuel cell hybrid system with super capacitor storage system. Energy 2020;192:116518. https://doi.org/10.1016/j.energy.2019.116518.

[15] Zhou D, Blaabjerg F. Bandwidth oriented proportional-integral controller design for back-to-back power converters in DFIG wind turbine system. IET Renew Power Gener 2017;11:941-51. https://doi.org/10.1049/iet-rpg.2016.0760.

[16] Youness EM, Aziz D, Abdelaziz EG, Jamal B, Najib EO, Othmane Z, et al. Implementation and validation of backstepping control for PMSG wind turbine using dSPACE controller board. Energy Rep 2019;5:807-21. https://doi.org/10.1016/j.egyr.2019.06.015. 
[17] Mensou S, Essadki A, Nasser T, Idrissi BB, Ben Tarla L. Dspace DS1104 implementation of a robust nonlinear controller applied for DFIG driven by wind turbine. Renew Energy 2020;147:175971. https://doi.org/10.1016/j.renene.2019.09.042.

[18] Ardjal A, Merabet A, Bettayeb M, Mansouri R, Labib L. Design and implementation of a fractional nonlinear synergetic controller for generator and grid converters of wind energy conversion system. Energy https://doi.org/10.1016/j.energy.2019.115861.

[19] Moussa I, Bouallegue A, Khedher A. New wind turbine emulator based on DC machine: hardware implementation using FPGA board for an open-loop operation. IET Circuits Devices Syst 2019;13:896-902. https://doi.org/10.1049/iet-cds.2018.5530.

[20] Dahbi A, Reama A, Hamouda M, Nait-Said N, Nait-Said M-S Control and study of a real wind turbine. Comput Electr Eng 2019;80:106492.

https://doi.org/10.1016/j.compeleceng.2019.106492.

[21] Yahyaoui I, Cantero AS. Modeling and Characterization of a Wind Turbine Emulator. Adv. Renew. Energ. Power Technol., Elsevier; 2018, p. 491-508. https://doi.org/10.1016/B978-0-12812959-3.00016-2.

[22] Famoso F, Brusca S, D’Urso D, Galvagno A, Chiacchio F. A novel hybrid model for the estimation of energy conversion in a wind farm combining wake effects and stochastic dependability. Appl Energy https://doi.org/10.1016/j.apenergy.2020.115967. 2020;280:115967.

[23] Mehrjerdi H. Modeling, integration, and optimal selection of the turbine technology in the hybrid wind-photovoltaic renewable energy system design. Energy Convers Manag 2020;205:112350. https://doi.org/10.1016/j.enconman.2019.112350.

[24] Kalaivani C, Rajambal K. Modeling of an efficient high power wind energy conversion system using self-excited multi-phase machines. Microprocess Microsyst 2020;74:103020. https://doi.org/10.1016/j.micpro.2020.103020.

[25] Alhato, Bouallègue. Direct Power Control Optimization for Doubly Fed Induction Generator Based Wind Turbine Systems. Math Comput Appl 2019;24:77. https://doi.org/10.3390/mca24030077.

[26] Pan L, Shao C. Wind energy conversion systems analysis of PMSG on offshore wind turbine using improved SMC and Extended State Observer. Renew Energy 2020;161:149-61. https://doi.org/10.1016/j.renene.2020.06.057.

[27] Sitharthan R, Karthikeyan M, Sundar DS, Rajasekaran S. Adaptive hybrid intelligent MPPT controller to approximate effectual wind speed and optimal rotor speed of variable speed wind turbine. ISA Trans 2020;96:479-89. https://doi.org/10.1016/j.isatra.2019.05.029.

[28] Mazen Alhato $M$, Bouallègue $S$, Rezk $H$. Modeling and Performance Improvement of Direct Power Control of DoublyFed Induction Generator Based Wind Turbine through SecondOrder Sliding Mode Control Approach. Mathematics 2020;8:2012. https://doi.org/10.3390/math8112012.

[29] Martinez F, Herrero LC, de Pablo S. Open loop wind turbine emulator. Renew Energy 2014;63:212-21. https://doi.org/10.1016/j.renene.2013.09.019.

[30] Imran RM, Akbar Hussain DM, Soltani M. DAC with LQR control design for pitch regulated variable speed wind turbine. 2014 IEEE 36th Int. Telecommun. Energy Conf. INTELEC, Vancouver, BC: IEEE; 2014, p. 1-6. https://doi.org/10.1109/INTLEC.2014.6972153.

[31] Chen J, Yao W, Zhang C-K, Ren Y, Jiang L. Design of robust MPPT controller for grid-connected PMSG-Based wind turbine via perturbation observation based nonlinear adaptive control Renew Energy 2019;134:478-95. https://doi.org/10.1016/j.renene.2018.11.048.

[32] Sajadi A, Rosłaniec $€$, Kłos M, Biczel P, Loparo KA. An emulator for fixed pitch wind turbine studies. Renew Energy 2016;87:391-402. https://doi.org/10.1016/j.renene.2015.10.033.
[33] Barambones O, Cortajarena JA, Calvo I, Gonzalez de Durana JM, Alkorta P, Karami-Mollaee A. Variable speed wind turbine control scheme using a robust wind torque estimation. Renew Energy https://doi.org/10.1016/j.renene.2018.10.009.

[34] Ouahabi MH, Elkhachine H, Benabdelouahab F, Khamlichi A. Comparative study of five different methods of adjustment by the Weibull model to determine the most accurate method of analyzing annual variations of wind energy in Tetouan - Morocco. Procedia Manuf 2020;46:698-707. https://doi.org/10.1016/j.promfg.2020.03.099.

[35] Bidaoui H, Abbassi IE, Bouardi AE, Darcherif A. Wind Speed Data Analysis Using Weibull and Rayleigh Distribution Functions, Case Study: Five Cities Northern Morocco. Procedia Manuf

2019;32:786-93 https://doi.org/10.1016/j.promfg.2019.02.286.

[36] Khalid Saeed M, Salam A, Rehman AU, Abid Saeed M. Comparison of six different methods of Weibull distribution for wind power assessment: A case study for a site in the Northern region of Pakistan. Sustain Energy Technol Assess 2019;36:100541. https://doi.org/10.1016/j.seta.2019.100541.

[37] Paraschiv L-S, Paraschiv S, Ion IV. Investigation of wind power density distribution using Rayleigh probability density function. Energy Procedia 2019;157:1546-52. https://doi.org/10.1016/j.egypro.2018.11.320.

[38] Serban A, Paraschiv LS, Paraschiv S. Assessment of wind energy potential based on Weibull and Rayleigh distribution models. Energy Rep 2020;6:250-67. https://doi.org/10.1016/j.egyr.2020.08.048.

[39] Google Maps, http://www.google.com/maps/; 2021 [accessed 13 Mars 2021].

[40] POWER Data Access Viewer, NASA power data, http://https://www.power.larc.nasa.gov/data-access-viewer/; 2021 [accessed 13 Mars 2021].

[41] Ahmed MM, Hassanein WS, Elsonbaty NA, Enany MA. Proposing and evaluation of MPPT algorithms for highperformance stabilized WIND turbine driven DFIG. Alex Eng J 2020;59:5135-46. https://doi.org/10.1016/j.aej.2020.09.043.

[42] Mousa HHH, Youssef A-R, Mohamed EEM. Variable step size P\&O MPPT algorithm for optimal power extraction of multiphase PMSG based wind generation system. Int J Electr Power Energy Syst 2019;108:218-31. https://doi.org/10.1016/j.ijepes.2018.12.044.

[43] Barrios Aguilar ME, Coury DV, Reginatto R, Monaro RM. Multiobjective PSO applied to PI control of DFIG wind turbine under electrical fault conditions. Electr Power Syst Res 2020;180:106081. https://doi.org/10.1016/j.epsr.2019.106081.

[44] Hu L, Xue F, Qin Z, Shi J, Qiao W, Yang W, et al. Sliding mode extremum seeking control based on improved invasive weed optimization for MPPT in wind energy conversion system. Appl Energy https://doi.org/10.1016/j.apenergy.2019.04.073.

[45] Cardenas R, Pena R. Sensorless Vector Control of Induction Machines for Variable-Speed Wind Energy Applications. IEEE Trans Energy Convers 2004;19:196-205. https://doi.org/10.1109/TEC.2003.821863.

[46] Yin M, Li W, Chung CYung, Zhou L, Chen Z, Zou Y. Optimal torque control based on effective tracking range for maximum power point tracking of wind turbines under varying wind conditions. IET Renew Power Gener 2017;11:501-10. https://doi.org/10.1049/iet-rpg.2016.0635.

[47] Kumar D, Chatterjee K. A review of conventional and advanced MPPT algorithms for wind energy systems. Renew Sustain Energy Rev 2016;55:957-70. https://doi.org/10.1016/j.rser.2015.11.013.

[48] Daili Y, Gaubert J-P, Rahmani L, Harrag A. Quantitative Feedback Theory design of robust MPPT controller for Small Wind Energy Conversion Systems: Design, analysis and 
experimental study. Sustain Energy Technol Assess 2019;35:30820. https://doi.org/10.1016/j.seta.2019.08.002.

[49] Karabacak M. A new perturb and observe based higher order sliding mode MPPT control of wind turbines eliminating the rotor inertial effect. Renew Energy 2019;133:807-27. https://doi.org/10.1016/j.renene.2018.10.079.

[50] Djilali L, Sanchez EN, Belkheiri M. Real-time implementation of sliding-mode field-oriented control for a DFIG-based wind turbine. Int Trans Electr Energy Syst 2018;28:e2539. https://doi.org/10.1002/etep.2539.

[51] Xiong L, Li P, Wang J. High-order sliding mode control of DFIG under unbalanced grid voltage conditions. Int $\mathrm{J}$ Electr Power Energy $\quad$ Syst $2020 ; 117: 105608$ https://doi.org/10.1016/j.ijepes.2019.105608.

[52] Naik KA, Gupta CP, Fernandez E. Design and implementation of interval type-2 fuzzy logic-PI based adaptive controller for DFIG based wind energy system. Int J Electr Power Energy Syst 2020;115:105468. https://doi.org/10.1016/j.ijepes.2019.105468.

[53] Bektache A, Boukhezzar B. Nonlinear predictive control of a DFIG-based wind turbine for power capture optimization. Int $\mathrm{J}$ Electr Power Energy Syst 2018;101:92-102. https://doi.org/10.1016/j.ijepes.2018.03.012.

[54] Ali MAS, Mehmood KK, Baloch S, Kim C-H. Modified rotorside converter control design for improving the LVRT capability of a DFIG-based WECS. Electr Power Syst Res 2020;186:106403. https://doi.org/10.1016/j.epsr.2020.106403.

[55] Abdeddaim S, Betka A. Optimal tracking and robust power control of the DFIG wind turbine. Int J Electr Power Energy Syst 2013;49:234-42. https://doi.org/10.1016/j.ijepes.2012.12.014. 
Improved hardware implementation of a TSR based MPPT algorithm for a low cost connected wind turbine emulator under unbalanced wind speeds

Dekali Zouheyr $^{\text {a }}$, Baghli Lotfi ${ }^{\mathrm{a}, \mathrm{b}}$, Boumediene Abdelmadjid ${ }^{\mathrm{a}}$

${ }^{a} L A T$, Laboratoire d'Automatique de Tlemcen, Université de Tlemcen13000, Tlemcen, Alegria

${ }^{b}$ Université de Lorraine, GREEN, EA 4366, Vandœuvre lès-Nancy, F-54500, France

\section{Tables}

Table 1 - WTE hardware component.

\begin{tabular}{ll}
\hline Component & Name \\
\hline 1,2 & Autotransformer (stator side, rotor side respectively) \\
3,4 & DFIG \& DCM respectively \\
5 & PC \\
6 & Inverter and Rectifier \\
7 & Fluke 43B Power Quality Analyzer \\
8,9 & Measure interfaces (DCM \& DFIG respectively) \\
10 & DS1104 interface \\
11 & Rheostat \\
12 & $\mathrm{~V}_{\mathrm{S}}, \mathrm{V}_{\mathrm{DC}}$ Measures \\
13 & Power supply (DCM excitation) \\
\hline
\end{tabular}

\begin{tabular}{ll}
\multicolumn{2}{l}{ Table 2 - WTE Settings. } \\
\hline Settings & Parameters \\
\hline $\mathrm{P}_{\mathrm{n}}$ & $1.5 \mathrm{~kW}$ \\
$\Omega_{\mathrm{m}}$ & $1500 \mathrm{rpm}$ \\
$\mathrm{R}$ & $3 \mathrm{~m}$ \\
$\mathrm{G}$ & 7 \\
$\beta$ & $2^{\circ}$ \\
$\lambda_{\text {opt }}$ & 11.68 \\
$\rho$ & 1.225 \\
\hline
\end{tabular}


Improved hardware implementation of a TSR based MPPT algorithm for a low cost connected wind turbine emulator under unbalanced wind speeds

Dekali Zouheyr $^{\text {a }}$, Baghli Lotfi ${ }^{\mathrm{a}, \mathrm{b}}$, Boumediene Abdelmadjid ${ }^{\mathrm{a}}$

${ }^{a} L A T$, Laboratoire d'Automatique de Tlemcen, Université de Tlemcen13000, Tlemcen, Alegria

${ }^{b}$ Université de Lorraine, GREEN, EA 4366, Vandœuvre lès-Nancy, F-54500, France

\section{Highlights}

- Experimental hardware description

- $\quad$ Modeling and control of WTE

- $\quad$ TSR Based MPPT algorithm structure

- $\quad$ The proposed WTE

- $\quad$ DFIG Modeling and control 